\title{
Continuing Professional Development for Doctors in Pakistan is need of the hour
}

\author{
Ahsan Sethi', Gohar Wajid ${ }^{2}$ \\ 1. Assistant Professor, Department of Medical Education, College of Health Sciences, Qatar University, Doha. \\ 2. Assistant Professor, Department of Medical Education, Imam Abdulrahman Bin Faisal Univeristy, Damman, SA.
}

doi: https://doi.org/10.53708/hpej.v3i1.714

This is an Open Access article and is licensed under a creative commons attribution (4.0 international License).

In Pakistan, health professionals get their professional undergraduate and postgraduate qualifications after thorough training and assessment criteria as defined by their respective national regulatory bodies. These qualifications help them get registered and get a license for clinical practice in their respective domains. Any registrations and licenses are renewed by paying the prescribed fee without any requirements for reassessment or recertifications.

Over the last few decades, health sciences have shown rapid advancements with the invention of new drugs and technologies. Due to this exponential increase in knowledge, no practitioner can hope to remain competent for more than a few years after graduation without a program of active learning. As such, a well-structured and regulated program of lifelong learning must be followed by all health professionals. To keep health professionals abreast with these changes and to ensure the maintenance of certain minimum competencies, there is a need for Continuing Professional Development (CPD) to be implemented at national level with strict regulatory compliance. According to World Federation for Medical Education (World Federation for Medical Education, 2015), Continuing Professional Development (CPD) is a process of education and training commencing after completion of basic and postgraduate medical education, thereafter, continuing as long as the health professional is engaged in professional activities. CPD mainly implies self-directed and practice-based learning activities in addition to supervised education, and rarely involves supervised training for any extended period of time.

The terms 'Continuing Medical Education (CME)' and 'Continuing Professional Development (CPD)' are often used synonymously. The American Medical Association and the AMA Council on Medical Education (American \& Association, 2017) defines CME as educational activities which serve to maintain, develop, or increase the knowledge, skills, and professional performance and relationships that a physician uses to provide services for patients, the public or the profession. The content of CME is the body of knowledge and skills generally recognized and accepted by the profession, within the basic/ clinical medical sciences for provision of healthcare to the public. Conceptually, a CME is a process of continuous learning to retain, upgrade and maintain professional competence,

\section{Correspondence:}

Dr. Ahsan Sethi

Assistant Professor, Department of Medical Education,

College of Health Sciences, Qatar University, Doha.

Email Address: ahsansethi@gmail.com while the scope of CPD stretches way beyond clinical update, includes wide-ranging competencies like research and scientific writing, medical education, multidisciplinary context of patient care, professionalism and ethical practice, communication, leadership, management and behavioral skills, team building, information technology, audit, and appropriate attitudinal change to ensure improved patient service and research outcomes and attainment of the highest degree of satisfaction by stakeholders. CPD includes other terms such as Continuing Medical Education (CME) or Continuing Dental Education (CDE) etc. These activities are beyond the scope of regular professional responsibilities of a doctor, conducted on routine basis. For example, regular clinicopathological conferences, morbidity and mortality meetings, regular lectures to students, teaching in ward rounds and other activities performed as routine job responsibility should not be considered as CPD activities.

Many countries have introduced formal CPD requirements at various levels, with few countries introducing it as an obligation and prerequisite for recertifications. The regulatory bodies and professional associations worldwide have developed formal mechanisms to ensure that the minimum competencies of health professionals are maintained at all times. If the health professionals are not provided with opportunities to update their knowledge and skills, it is likely that they will not be able to transfer the benefits of advancements in medicine to the population they serve.

In Pakistan, CPD has always existed as an informal learning activity based on the individuals' voluntary interest or opportunity provided by the workplace or professional associations. These may or may not cover the demands of evolving healthcare practices. It has remained generally unstructured and unscheduled with weak regulatory support from the then Pakistan Medical and Dental Council. The regulatory framework backed by the national CPD policy and well-structured plan and infrastructure to implement CPD from top to grass root level has been missing. For effectiveness, there is a need for introducing CPD formally and in a structured manner.

Previously, the College of Physicians and Surgeons Pakistan (CPSP, 2005) in collaboration with World Health Organisation developed a draft national policy in 2002-03, which led to the development of national strategic plan in 2004-05. However, it was never implemented. In August 2009, the then Pakistan Medical and Dental Council in collaboration with WHO and 
other stakeholders from various academic institutions and professional associations, developed guiding principles for the CPD program for Pakistan (PMDC, 2009). It was agreed that the then Pakistan Medical and Dental Council (Now Pakistan Medical Commission) should develop CPD program with active participation of key stakeholders and ensure its effective implementation at all levels. In 2012, PMDC developed National $\mathrm{CME} / \mathrm{CDE}$ guidelines (PMDC, 2012) and implemented them as well, but unfortunately the program failed, primarily due to the lack of technical capacity in the PMDC office to implement and effectively monitor it.

As part of Medical Education Committee (MEC), in 2018, we proposed a National Continuing Professional Development Program (CPD) for Pakistan, based on the principles of lifelong learning and continuous quality improvement of clinical and professional competencies, primarily based on the needs of the people of Pakistan and in-line with global trends. The CPD should not only focus on promoting evidence-based practice of their specialties but also include skills related to research, professionalism and ethics, leadership, management, communication, information technology, medical education as deemed necessary for carrying ones general and specific professional responsibilities.

The policies and guidelines developed by MEC, were endorsed by the Executive Committee of the then Pakistan Medical and Dental Council (Now PMC). We believe that Pakistan Medical Commission (Previously Pakistan Medical and Dental Council) as federal regulatory authority should consult technical experts to review those standards, policies and guidelines. They should also establish a department of CPD to implement and regulate CPD programs, provide technical support and perform periodic evaluation for ensuring quality. PMC shall issue a list of all CPD approved activities, CPD providers and review them periodically as deemed necessary. The cardinal focus of the National CPD Program shall be based on country needs, perceptions and prevailing practices among physicians. The organization and delivery of CPD needs to be shaped in the context of globalization of health, cross-country migration of medical workforce, evidence-based practice, changing contents to meet societal, demographic, cost-effective demands, and also varied trends in assessment of professional competence. $\mathrm{CPD}$ providers may include medical universities, postgraduate medical institutes, medical colleges, hospitals, professional associations and societies, Colleges of specialties, scientific and professional institutes, NGOs, not for profit organizations and international organizations of similar nature, from both public and private sectors. Participation in CPD activities may be online or face to face/blended. CPD activities may include, but are not limited to conferences, seminar, congress, symposium, peer review of articles and other research activities, workshops, short courses, poster presentation, publications etc. The CPD department shall develop an electronic CPD Information System to collect data related to CPD activities at CPD user, CPD provider, institutional and national levels. The CPD department should maintain effective liaison with medical universities to appoint observers and effectively manage CPD activities across the country. The Government of Pakistan should provide the initial funding to establish National CPD program, and its essential infrastructure. Once successfully implemented, CPD credits should be linked with recertification and renewal of licenses. To conclude, we believe that a Continuing Professional Development program for Pakistan is need of the hour. Engaging in CPD should be seen as a professional obligation and a prerequisite for enhancing the quality of healthcare. The strongest motivating factor for continuing professional learning should be the will and desire to maintain professional quality.

\section{REFERENCES}

American, T., \& Association, M. (2017). The AMA Physician 's Recognition Award and credit system.

Continuing Medical Education: National policy and strategic guidelines for Pakistan, College of Physicians and Surgeons Pakistan. 2005.

Pakistan Medical \& Dental Council; Guidelines for Continuing Medical Education, Continuing Dental Education. 2012.

Pakistan Medical and Dental Council; National consultation on continuing professional development. 2009.

World Federation for Medical Education. (2015). Continuing Professional Development of Medical Doctors WFME Global Standards for The 2015 Revision. 1-56. Retrieved from https:// wfme.org/download/wfme-global-standards-cpd-english/ 